\title{
Milky hemolymph syndrome (MHS) in spiny lobsters, penaeid shrimp and crabs
}

\author{
Linda M. Nunan ${ }^{1, *}$, Bonnie T. Poulos ${ }^{2}$, Solangel Navarro ${ }^{1}$, Rita M. Redman ${ }^{1}$, \\ Donald V. Lightner ${ }^{1}$
}

${ }^{1}$ Department of Veterinary Science and Microbiology, and ${ }^{2}$ Department of Ecology and Evolutionary Biology, University of Arizona, Tucson, Arizona 85721, USA

\begin{abstract}
Black tiger shrimp Penaeus monodon, European shore crab Carcinus maenas and spiny lobster Panulirus spp. can be affected by milky hemolymph syndrome (MHS). Four rickettsia-like bacteria (RLB) isolates of MHS originating from 5 geographical areas have been identified to date. The histopathology of the disease was characterized and a multiplex PCR assay was developed for detection of the 4 bacterial isolates. The 16S rRNA gene and 16-23S rRNA intergenic spacer region (ISR) were used to examine the phylogeny of the MHS isolates. Although the pathology of this disease appears similar in the various different hosts, sequencing and examination of the phylogenetic relationships reveal 4 distinct RLB involved in the infection process.
\end{abstract}

KEY WORDS: Rickettsia-like bacteria $\cdot$ Decapod crustaceans $\cdot$ Milky hemolymph syndrome $\cdot$ MHS Resale or republication not permitted without written consent of the publisher

\section{INTRODUCTION}

Milky hemolymph syndrome (MHS) is a descriptive name for a group of similar diseases affecting spiny lobsters, penaeid shrimp and crabs. The syndrome is so named because the hemolymph of the affected decapods becomes increasingly turbid and turns 'milky' in appearance in severely infected individuals. The turbidity is due to the massive numbers of rickettsia-like bacteria (RLB) circulating in the hemolymph. Increased turbidity (e.g. the more milky appearance) of the hemolymph generally relates to increases in the moribund state of affected individuals. Milky hemolymph is not pathognomonic for MHS, as infection of decapods by a variety of agents can result in the presentation of milky hemolymph. Noteworthy examples of recently described crustacean diseases in which milky hemolymph has been reported include systemic infection by Streptococcus sp. (Hasson et al. 2009), a herpes-like virus (Shields \& Behringer 2004) and a parasitic dinoflagellate in the genus Hematodinium (Xu et al. 2010). Like the rickettsia-like bacteria discussed in the present paper, Hematodinium spp. affect a wide range of crustaceans, including shrimp, crabs and lobsters and generally present similar gross signs including lethargy, discolored carapace and hemolymph that is milky and does not clot (Field et al. 1992, Li et al. 2008, $\mathrm{Xu}$ et al. 2010). The streptococcal infection of Litopenaeus vannamei characterized by Hasson et al. (2009) caused the hemolymph to appear opaque and milky as a result of the high concentrations of circulating bacteria, which prevented the hemolymph from clotting.

MHS has been reported in black tiger shrimp Penaeus monodon farmed in east Africa and Madagascar (Nunan et al. 2003), wild European shore crabs Carcinus maenas (Eddy et al. 2007) and in cultured spiny lobsters Panulirus spp. in Vietnam (Lightner et al. 2008). Because it briefly threatened the developing spiny lobster farming industry in Vietnam (Lightner et al. 2008), milky hemolymph disease (MHD = MHS) in spiny lobsters was listed in the Office international des épizooties Aquatic Animal Health Code (OIE 2009) as 'under study' for possible listing as a notifiable disease of Panulirus spp. Similar systemic RLB-caused diseases have been seen previously in farmed Penaeus monodon from Malaysia (Anderson et al. 1987, Brock 1988) and in wild crabs Carcinus mediterraneus collected in France (Bonami \& Pappalardo 1980). Hence, MHS may 
be an 'old' disease that has been overlooked or kept under control through the use of medicated feeds used for treating other bacterial infections.

This study examines the histopathology associated with MHS in various decapod species from 5 different geographical regions (Madagascar, Mozambique, Tanzania, UK and Vietnam), the development of a multiplex PCR assay for simultaneously detecting the agents associated with the disease and the phylogenetic relationships among the RLB, based on the $16 \mathrm{~S}$ rRNA gene and 16-23S ribosomal RNA (rRNA) intergenic spacer region.

\section{MATERIALS AND METHODS}

Histopathology. Samples of Penaeus monodon and Panulirus spp. were preserved in Davidson's AFA fixative (Bell \& Lightner 1988) for histopathological examination. Tissues were processed and embedded in ParaPlast Xtra paraffin (Fisher Scientific) and sectioned at $4 \mu \mathrm{m}$ thickness. The sections were mounted onto microscope slides and stained with haematoxylin and eosin (H\&E) (Lightner 1996) or the Gram-Twort tissue Gram stain (Drury \& Wallington 1967). Histological examination of the processed samples was performed with standard light microscopy. Routine H\&E stained histological sections from samples of Carcinus maenas with MHS were processed by Eddy et al. (2007), while in situ hybridization assays run with sections of $C$. maenas were part of the present study.

In situ hybridization. Carcinus maenas samples, preserved in Davidson's AFA fixative, embedded in ParaPlast Xtra paraffin and sectioned at $4 \mu \mathrm{m}$ thickness were mounted onto positively charged microscope slides (Fisher Scientific). The digoxygenin-labeled probe was generated by PCR using primers previously published by Eddy et al. (2007). The in situ hybridization assays were performed as detailed by Eddy et al. (2007).

MHS isolates, necrotizing hepatopancreastitis bacterium (NHP-B) and Photobacterium spp.: DNA extractions. DNA was extracted from either frozen or ethanol-preserved shrimp or lobster tissues using the High Pure PCR Template Preparation Kit (Roche Diagnostics). DNA from Carcinus maenas infected with MHS was supplied by F. Eddy (Swansea University).

Specificity bacterial panel: DNA extractions. Six bacterial cultures from the University of Arizona (UAZ) culture collection (geographical origin of isolate in parentheses) comprising Vibrio penicida (New Caledonia), V. vulnificus (Hawaii, USA), V. alginolyticus (Madagascar), V. parahaemolyticus (Madagascar), V. fluvialis (Louisiana, USA) and Aeromonas sp. (Arizona, USA) were cultured on a shaker platform at room tem- perature in $5 \mathrm{ml}$ tryptic soy broth (DIFCO) supplemented with $1 \% \mathrm{NaCl}$. Spiroplasma penaei was cultured in M1D media as previously described (Nunan et al. 2004). The bacterial cultures were centrifuged at $6000 \times g$ for 3 min and the DNA was extracted from the pellets using the High Pure PCR Template Preparation Kit.

Amplification of the 16S rRNA gene and the 16-23S rRNA ISR. Extracted DNA from all of the samples was amplified using universal 16S rRNA primers (Nunan et al. 2003). Amplification of the bacterial panel was also necessary to test the integrity of the DNA. The extracted DNA from the RLB was also amplified by PCR with 16-23S rRNA ISR primers (Lu et al. 2009) to obtain the additional sequence information for the respective RLB geographical isolates.

Selection of isolate-specific primers. All of the primers used in the multiplex PCR reaction were derived from the 16-23S rRNA ISR sequence information. Primer pairs for the various geographical isolates were designed with Primer Designer 4 (Scientific and Educational Software). The primers were synthesized by Eurofins MWG/Operon (Huntsville, Alabama). The primer pairs were initially tested by PCR using the DNA from the isolate from which the sequence data was generated before being assessed in the multiplex PCR reaction.

Multiplex amplification. The DNA that was used for PCR amplification using the 16S rRNA and 16-23S rRNA ISR primers was also used as the template in the multiplex PCR assay to determine the MHS isolate. PCR beads (illlustra ${ }^{\mathrm{TM}}$ PuReTaq ${ }^{\mathrm{TM}}$, Ready-To-Go ${ }^{\mathrm{TM}}$, in $0.5 \mathrm{ml}$ tubes) were used in the PCR reaction mixture of $25 \mu \mathrm{l}$ volume that contained $22.5 \mu \mathrm{l}$ sterile $\mathrm{H}_{2} \mathrm{O}, 0.25 \mu \mathrm{l}$ of each primer $(5 \mu \mathrm{M})$ (Table 1$)$ and $1.0 \mu \mathrm{l}$ of DNA template (50 to $100 \mathrm{ng} / \mu \mathrm{l}$ ). The optimized thermal cycling program consisted of an initial denaturing step for 3 min at $95^{\circ} \mathrm{C}$, followed by 40 cycles of denaturation for $15 \mathrm{~s}$ at $95^{\circ} \mathrm{C}$, annealing for $20 \mathrm{~s}$ at $63.5^{\circ} \mathrm{C}$ and extension

Table 1. Sequences of PCR oligonucleotide primers, $5^{\prime}$ to $3^{\prime}$ orientation, that generate the following amplicons in the respective geographical isolates: $939 \mathrm{bp}$ for Madagascar, $656 \mathrm{bp}$ for Vietnam, $550 \mathrm{bp}$ for Mozambique and Tanzania and 266 bp for the UK. F: forward; R: reverse

\begin{tabular}{|c|c|}
\hline Primer & Sequence \\
\hline Madagascar F & CAT GCT ACG TCC TTC ATC \\
\hline Madagascar R & GCT CCA CCA ATG CTA TCT \\
\hline Tanzania F & GTA GCG TAA CCT GGC GTT CT \\
\hline Tanzania $\mathrm{R}^{\mathrm{a}}$ & AGC GTA CCA CGT CCT TCA TC \\
\hline United Kingdom $F^{a}$ & TAT TCA GGG CCT GTA GCT CA \\
\hline United Kingdom R & ATC AAG CAC CTG GCT TTA CC \\
\hline $\begin{array}{l}{ }^{\text {aPrimer combination }} \\
\text { plicon }\end{array}$ & that generates Vietnam isolate am- \\
\hline
\end{tabular}


for $30 \mathrm{~s}$ at $72^{\circ} \mathrm{C}$, ending with 1 cycle for 2 min at $72^{\circ} \mathrm{C}$. The amplified products were held at $4^{\circ} \mathrm{C}$ at the completion of the cycling program. The PCR products were analyzed on a $1.0 \%$ agarose gel in tris-borate-EDTA (TBE) buffer containing $0.5 \mu \mathrm{g} \mathrm{ml}^{-1}$ ethidium bromide.

Cloning and sequencing the genes. The PCR amplicons were ligated with T4 DNA ligase using the pGEM T-Easy Vector System (Promega) and transformed in JM109 competent cells following the manufacturer's protocol. The transformed bacteria were plated onto Luria-Bertani (LB)-amp plates containing Xgal (5bromo-4-chloro-3-indolyl- $\beta$-D-galactoside) and IPTG (isopropyl-1-thio- $\beta$-D-galactoside). Plates were incubated overnight at $37^{\circ} \mathrm{C}$. White colonies were screened using M13 forward and reverse primers. The clones containing the correct size amplified fragment from the M13 screening were subcloned and a single colony was cultured in LB broth overnight at $37^{\circ} \mathrm{C}$ on a shaker platform. DNA was extracted from the cultures using the E.Z.N.A. Plasmid Mini Kit (Omega Bio-Tek). The eluted DNA concentration was determined at $260 \mathrm{~nm}$ using a BioPhotometer (Eppendorf) and sequenced at the UAZ Research Laboratory DNA Sequencing Facility.

Phylogenetic analysis. Phylogenetic analysis was conducted using MEGA v. 4 (Tamura et al. 2007). Alignment Explorer/CLUSTAL in MEGA 4.0 was used to align the DNA sequences generated from this study. Two dendrograms were constructed using the Neighbor-Joining (NJ) method, one using the 16S rRNA gene and the other from the 16-23S rRNA ISR sequences. The robustness for individual branches was estimated by bootstrapping with 1000 replications. NHP-B, another common rickettsia-like bacterial pathogen of shrimp, was included in both analyses as an outlier.

\section{RESULTS}

\section{Gross signs and histology}

Penaeus monodon, Panulirus spp. and Carcinus maenas with severe MHS present similar gross signs and histopathology. Severely affected individuals become lethargic, cease feeding and become moribund. Hemolymph exuding from wounds or when drawn into a syringe is turbid, appearing milky in severely affected specimens. The hemolymph from severely affected individuals does not clot.

The histopathology presented by shrimp, spiny lobsters and crabs is remarkable and very similar. Mesodermally derived tissues are the primary target tissues for RLB in MHS. In shrimp, the first and most severely affected organ appears to be the lymphoid organ (LO)
(Figs. 1c \& 2a,b), followed by connective tissue elements of most other tissues (e.g. the capsule of the hepatopancreas [HP], the serosal layers of the foregut, midgut, midgut caeca and heart), circulating hemocytes and fixed phagocytes in the hemocoel of the heart and gills. The hemolymph of severely affected shrimp visible in the hemocoel within the LO, HP, gills, heart and other tissues stains bluish with $\mathrm{H} \& \mathrm{E}$ due to the presence of large amounts of RLB (data not shown).

Spiny lobsters and crabs present a similar histopathology to that presented by shrimp. Spiny lobsters and crabs lack a LO, but otherwise the lesions produced by infection by the respective RLB appear essentially identical, as illustrated by sections through the heart, HP and gills. As was found in shrimp, RLB literally fill connective tissue cells and fixed phagocytes and cause enormous hypertrophy in a variety of tissues (Fig. 2c,d,e). Free RLB in the hemolymph causes it to stain bluish with H\&E or dark blue-black by in situ hybridization (ISH) (Fig. 2a-f). Mucosal epithelial cells of the HP and midgut are apparently not infected by RLB and appear normal (Fig. 2d,f).

\section{Multiplex PCR}

DNA extracted from the MHS isolates was amplified by PCR using both the 16S rRNA universal primers and the MHS-specific primer pairs. Additional DNA templates from NHP-B, Photobacterium spp., and 7 bacterial species grown from culture (UAZ) were also assessed by PCR using the 16S rRNA primers. Amplified fragments of approximately 1200 to $1300 \mathrm{bp}$ were generated in all samples amplified by PCR using the 16S rRNA primers (data not shown). This initial test was necessary to confirm the integrity of the DNA templates used for the subsequent specificity testing. PCR amplification occurred only in the MHS samples using the 3 primer pairs in the multiplex PCR reaction. Using the optimized thermal cycling program, there were no amplicons generated in any of the other bacterial samples screened (Fig. 3).

The primers employed in the multiplex PCR reaction for the MHS isolates were specifically designed from the 16-23S rRNA ISR of Madagascar, Tanzania and UK sequences. The expected amplicons from these isolates, based on the sequence information, should have been 311, 550 and $266 \mathrm{bp}$, respectively. Both Tanzania and Mozambique isolates, detected in this assay, generated $550 \mathrm{bp}$ fragments. The UK isolate amplicon was the expected $266 \mathrm{bp}$. The Madagascar and Vietnam MHS isolates generated amplicons of unexpected sizes, 939 and $656 \mathrm{bp}$, respectively. The fragments were cloned and sequenced. The results showed that the amplicons originated from 16-23S 

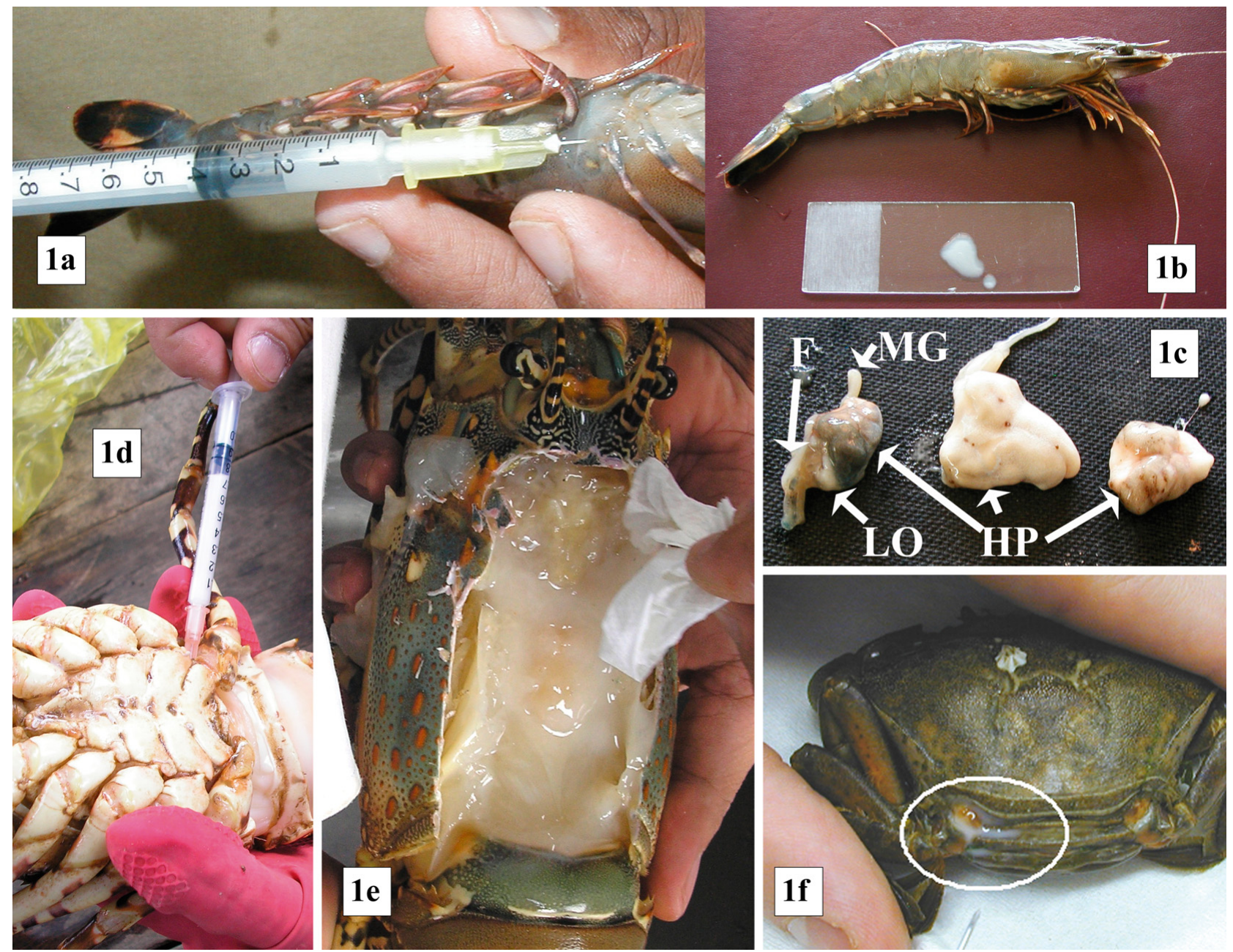

Fig. 1. Examples of milky hemolymph syndrome (MHS) in subadult black tiger shrimp Penaeus monodon, spiny lobster Panulirus sp. and European shore crab Carcinus maenas. (a) Turbid (milky-looking) hemolymph being drawn from the ventral hemocoel sinus of $P$. monodon. (b) A drop of turbid hemolymph on a glass slide from the same shrimp as in (a). (c) Excised hepatopancreata (HP) and adjacent organs (foregut, anterior midgut, anterior midgut caecum and lymphoid organ) from 3 P. monodon. The HP on the left shows few grossly apparent MHS lesions except for the lymphoid organ (LO), which lies ventral to the foregut and is enlarged and distinctly white, and some relatively small developing lesions in the dorsal serosa of the foregut $(\mathrm{F})$ and of the anterior midgut (MG) serosa. The HPs in the center and right are severely affected and have prominent MHS lesions, which are apparent in the connective tissue capsule of the HP, and are severely affecting the foregut, anterior MG and LO, making them nearly unrecognizable. (d) Turbid ('milky' looking) hemolymph being drawn from a hemocoel sinus of an adult Panulirus sp. (e) A portion of the carapace from the same lobster as in (d) has been removed exposing the underlying hemocoel, subcuticular connective tissues and the region where the heart, gonads and hepatopancreas should be apparent. 'Milky' looking hemolymph and connective tissue cells filled with the rickettsia-like bacteria mask the underlying organs. (f) Carcinus maenas with turbid ('milky' looking) hemolymph exuding from a puncture wound (circled) made at the junction of the carapace and abdomen by the syringe needle that is visible in the lower part of the image

rRNA ISR (Madagascar nucleotide [nt] 328 to nt 1267; Vietnam nt 160 to nt 816).

\section{Sequence analysis and phylogenetics}

Comparisons of the 16S rRNA gene sequences from the Mozambique and Tanzania isolates revealed $98 \%$ homology between the 1252 and 1258 bp amplicons. A $99 \%$ homology between the 678 and $677 \mathrm{bp}$ sequences from the 16-23S rRNA ISR from Mozambique and Tanzania was determined. The sequences from the 5 MHS isolates generated by the 16S rRNA primers were approximately the same length (1220 to 1258 bases), but when the same isolates were amplified using the 16-23S rRNA ISR primers the 

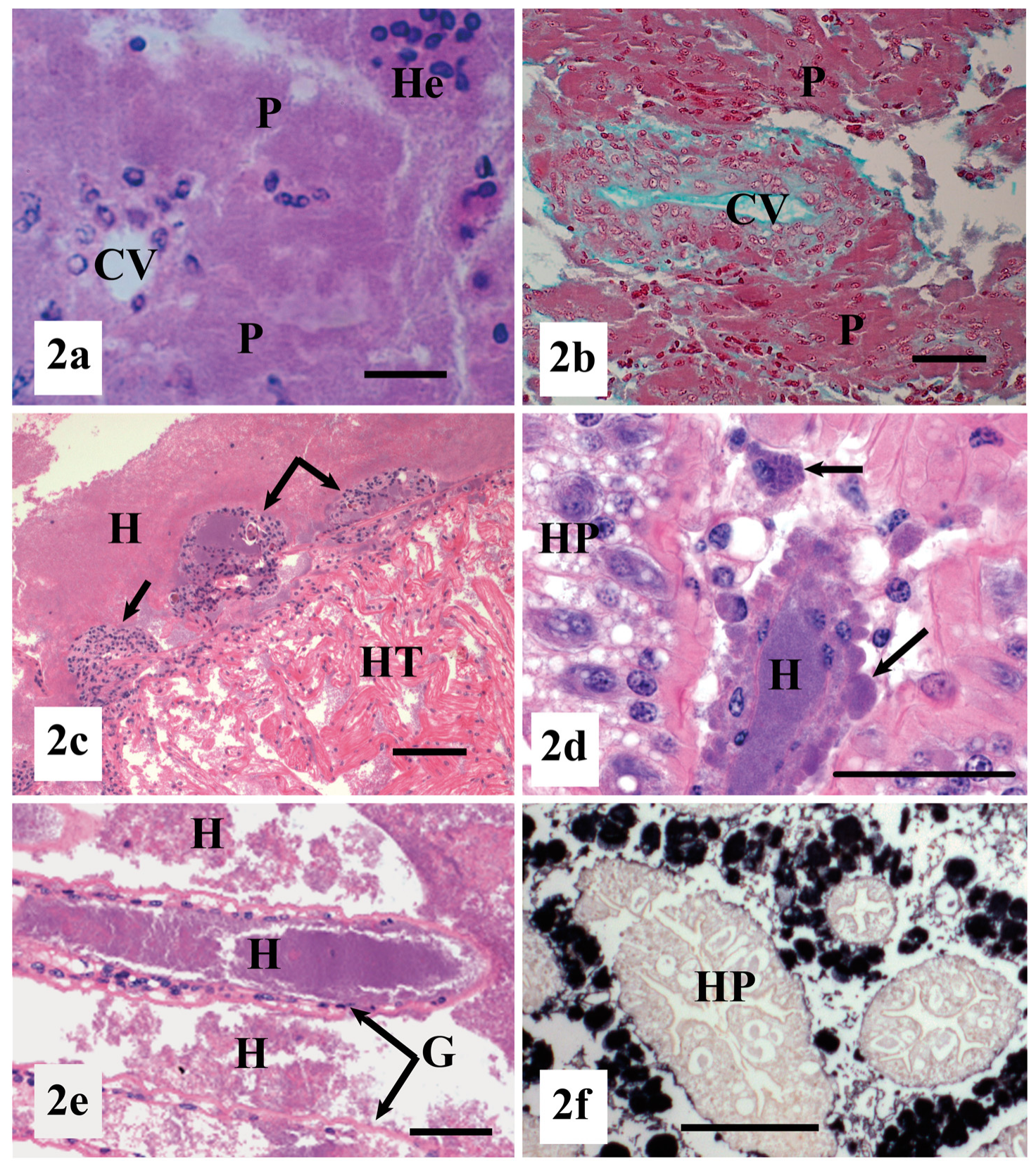

Fig. 2. Examples of MHS lesions in tissues of subadult black tiger shrimp Penaeus monodon, an adult spiny lobster Panulirus sp. and a European shore crab Carcinus maenas. (a) Section through the lymphoid organ (LO) of a P. monodon individual that is severely affected by MHS. Shown is a central vessel (CV) surrounded by parenchymal (P) cells with their cytoplasm filled with masses of the grey-blue staining rickettsia-like (RLB) agent. Aggregates of necrotic hemocytes (He) are apparent in the right and upper right of the image. H\&E stain, scale bar $=20 \mu \mathrm{m}$. (b) Parallel section to that shown in (a), but stained with the Gram-Twort stain. A distinct LO tubule with an intact central vessel (CV) is shown among disrupted LO tubules with P cells whose cytoplasm is filled with masses of very small Gram-negative bacteria. Gram-Twort stain, scale bar $=500 \mu \mathrm{m}$. (c) Section through the heart and adjacent hemocoel of an adult Panulirus sp. with MHS. Hemolymph (H) in the hemocoel adjacent to the heart (HT) and among the cardiac muscle fibers has a blue-grey hue due to the abundance of RLB. Hemocytic nodules (arrows) around masses of the RLB are apparent in the connective tissue capsule of the heart. H\&E stain, scale bar $=100 \mu \mathrm{m}$. (d) Section through the hepatopancreas (HP) of an adult Panulirus sp. with MHS. In the intertubular spaces of an otherwise normal HP, several presumed heomcytes or fibrocytes (arrows) have developing cytoplasmic inclusions with masses of RLB. An arteriole with a mass of darkly stained RLB in the hemolymph of the lumen is prominent in the center of the image. H\&E stain, scale bar $=50 \mu m$. (e) Sections through the gills of an adult Panulirus sp. with MHS. Masses of RLB are present in the H located in the gill filaments (G) as well as in masses of hemorrhaged hemolymph present between the gill filaments. H\&E stain, scale bar $=50 \mu \mathrm{m}$. (f) Section through the hepatopancreas of Carcinus maenas with MHS and reacted by in situ hybridization (ISH) with a specific digoxigenin DNA probe to the crab RLB. Present in the intertublar spaces of an otherwise normal HP are numerous connective tissue cells and fixed phagocytes whose cytoplasm has stained black due to their being filled with the RLB. ISH with Bismarck Brown counterstain, scale bar $=200 \mu m$ 


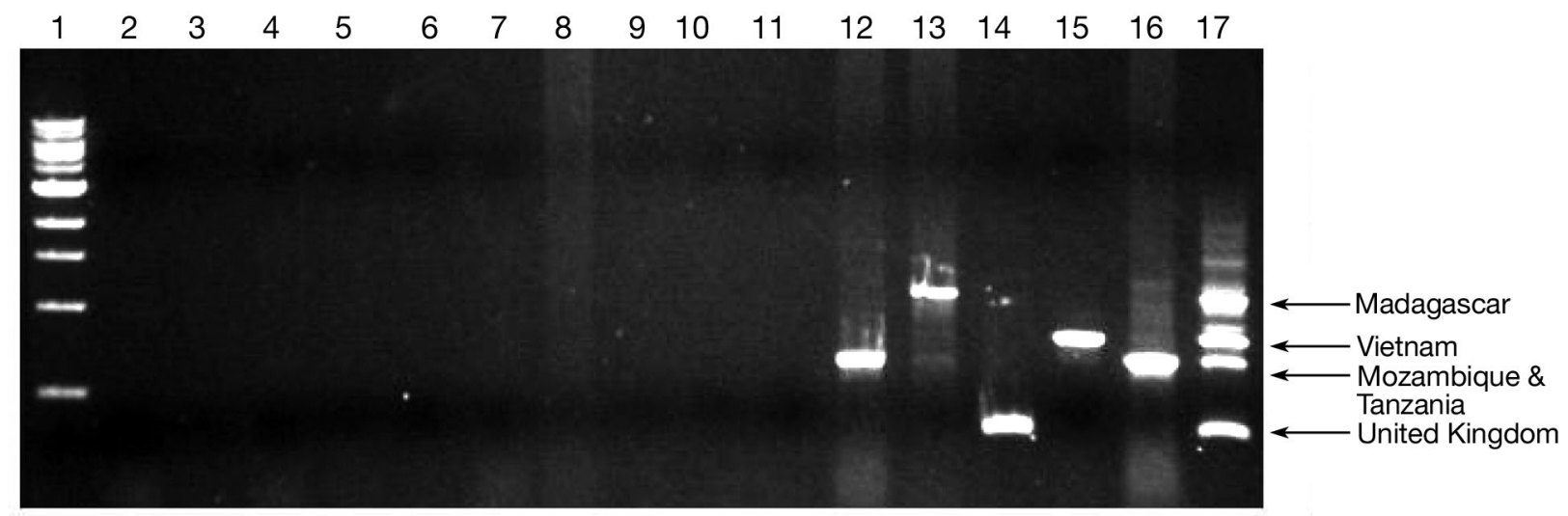

Fig. 3. Electrophoretic pattern in a $1 \%$ agarose gel using the multiplex primer pairs. Lane 1: 1 kb DNA marker; Lane 2: Vibrio penicida; Lane 3: V. vulnificus; Lane 4: V. alginolyticus; Lane 5: V. parahaemolyticus; Lane 6: V. fluvialis; Lane 7: Aeromonas sp; Lane 8: Necrotizing hepatopancreas titis (NHP-B); Lane 9: Photobacterium sp.; Lane 10: Spiroplasma penaei; Lane 11: No template $\left(\mathrm{H}_{2} \mathrm{O}\right)$; Lane 12: Mozambique; Lane 13: Madagascar; Lane 14: UK; Lane 15: Vietnam; Lane 16: Tanzania; Lane 17: Positive control

sequence lengths varied from 677 to $1340 \mathrm{bp}$. The Vietnam isolate sequence was $879 \mathrm{bp}$ and the Madagascar and UK isolates were 1340 and 1333 bp, respectively. Even though the Madagascar and UK isolates were of similar nucleotide number, minimal homology $(<50 \%)$ was present between the 2 sequences.
Phylogenies, based on partial DNA sequences of the 16S rRNA and the 16-23S rRNA ISR (Fig. 4a,b) of the 5 MHS isolates were reconstructed for each locus individually using the distance-based NJ method. The unrooted NJ dendrograms, based on the DNA sequences investigated in this study, showed strong bootstrap support for the Tanzania and Mozambique MHS isolates.
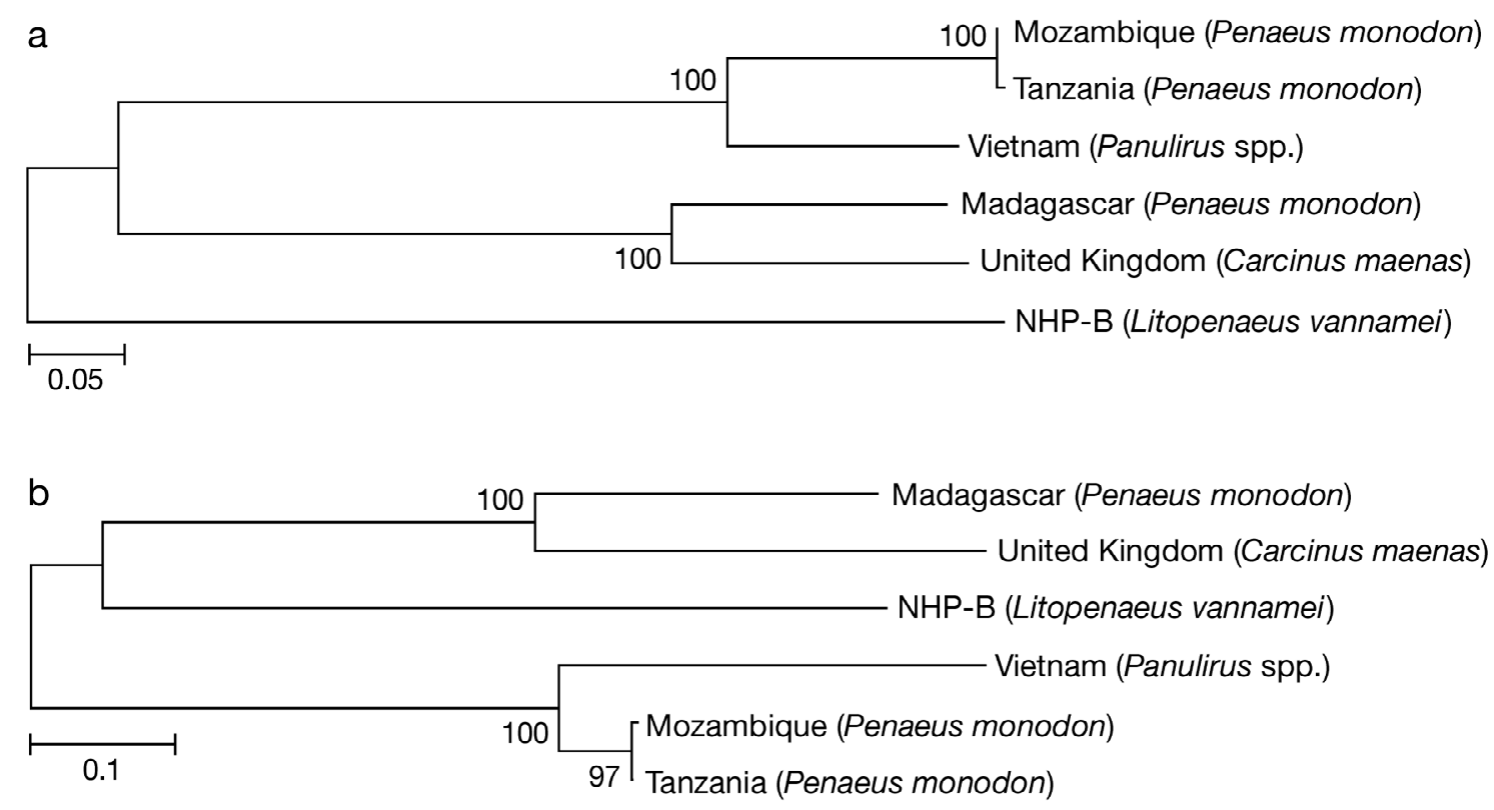

Fig. 4. Phylogenetic relationship of 5 milky hemolymph syndrome isolates (GenBank accession numbers in parentheses). (a) Madagascar (GU947656), Mozambique (GU947655), Tanzania (GU947657), Vietnam (GU947658) and UK (AM749067) based on the 16S rRNA gene and inferred using the neighbor-joining (NJ) method based on comparison of 1220 to 1258 bases. Necrotizing hepatopancreatitis bacterium (NHP-B; U65509) was used as the outlier. (b) Madagascar (GU947659), Mozambique (GU947660), Tanzania (GU947661), Vietnam (GU947662) and the UK (GU947813) based on the 16-23S rRNA ISR and inferred using the NJ methodbased on comparison of 641 to 1340 bases. NHP-B (GU947814) was used as the outlier 


\section{DISCUSSION}

The present paper documents the occurrence of MHS in 3 diverse decapod crustaceans. MHS was found in shrimp Penaeus monodon, crab Carcinus maenas and spiny lobster Panulirus spp. from 5 geographical areas that included East Africa and Madagascar, Vietnam and the UK. Previous literature on MHS-like diseases caused by RLB suggest that the disease may be an 'old' disease (Bonami \& Pappalardo 1980, Anderson et al. 1987, Brock 1988), which may have reemerged in a new decapod species in new regions where they were farmed or held captive for other reasons. Four distinct RLB were found to be associated with, and were most probably the causative agents of, MHS in these decapod species. That MHS has been found on 3 continents in tropical and temperate locations, as well as in a diverse group of hosts for the 4 recognized RLB agents of the disease, suggests that other decapods may be hosts for these or other similar agents.

The histopathology of MHS in the shrimp, spiny lobsters and crabs in the present study is very similar. In all 3 of these species the RLB agents associated with the disease progressively invade mesodermally derived tissues including the LO (in shrimp), connective tissues, circulating hemocytes and fixed phagocytes. The cuticular epithelium, striated muscles and the muscosal cells of the hepatopancreas and midgut are either unaffected or minimally affected. In advanced infections, a huge number of free RLB are released into the hemolymph from enormously hypertrophied infected cells, making the hemolymph turbid and of milky appearance in the most severely affected individuals. The destruction of circulating hemocytes results in hemolymph that does not clot and will freely exude from wounds, which in conjunction with organ dysfunction is likely to contribute to morbidity and mortality.

The ability to distinguish the MHS isolates through the use of a single PCR multiplex assay was contingent upon sequencing the 16-23S rRNA ISR. Sequences generated from the 16S rRNA gene were too similar for the development of a PCR assay that detected the individual isolates. By incorporating 6 primers in the multiplex reaction, all of the MHS geographical isolates were detected in a single PCR test. Although specific primers designed for the Vietnam isolate were not included in the PCR reaction mixture, a 656 bp amplicon was generated. This amplified fragment corresponded to the 16-23S rRNA ISR sequence of the Vietnam isolate. The Vietnam isolate was amplified using the combination of the UK forward and Tanzania reverse primers, even though the UK primer was only $70 \%$ homologous to the 16-23S rRNA sequence (14 bp fully homologous to the 3 primer end). Theoretically, the amplicon generated using the primers specific to the Madagascar isolate should have been 541 bp, but in fact was 939 bp. This larger fragment was fully homologous when compared with the 16-23S rRNA ISR derived from the Madagascar isolate. The multiplex PCR assay developed for distinguishing the MHS isolates was determined to be specific after testing various bacterial species. Only MHS samples showed amplification.

In other organisms, the 16-23S rRNA ISR can be variable in length. Avian Mycoplasma species yielded PCR products between 400 and 3000 bp when universal 16-23S rRNA primers were employed (Ramírez et al. 2008). There are 6 spacer classes with sizes of 706 , $669,527,524,431$ and 278 bp present in various Vibrio parahaemolyticus clinical strains (Gonzalez-Escalona et al. 2006). Since the bacteria associated with MHS are unrelated, with the exception of Tanzania and Mozambique, assumptions cannot be drawn as to the size differences between the ISRs, but mutations, deletions and multiple copies of operons most probably have contributed to the size differentials.

Analysis of the dendrograms further supported how closely the bacteria were related. The trees based on the 16S rRNA gene and the 16-23S rRNA ISR sequences grouped Mozambique and Tanzania. Strong bootstrap support was shown for the Tanzania and Mozambique isolates, which was supported by the percentage of highly homologous sequences generated from the 16S rRNA gene (98\%) and 16-23S rRNA ISR (99\%). The Vietnam isolate was most closely related to both Mozambique and Tanzania based on the percentage of homology between the 16S rRNA gene sequences $(96 \%)$, and in both dendrograms Vietnam grouped with Mozambique and Tanzania. Madagascar and UK MHS isolates were closely related in the dendrogram based on the 16Sr RNA gene and also when the homology of the 16S rRNA gene sequences were compared, in which $94 \%$ of the nucleotides were homologous. These isolates appear to be more distantly related when the 16-23S rRNA ISR tree was examined. Sequence homology based on the 16S rRNA gene was $96 \%$, but when the 16-23S rRNA ISR sequences were compared, minimal homology was present. Generating additional sequence data from the 16-23S rRNA ISR was necessary for both the development of the multiplex PCR assay and for determination of the genetic relatedness of the $5 \mathrm{MHS}$ geographical isolates.

Acknowledgements. Funding for this work was provided by US Department of Agriculture CSREES grant number 200838808-19163 and support from the National Fisheries Institute. The authors thank Dr. F. Eddy for supplying the Carcinus maenas MHS isolate and for allowing publication of the photograph of the shore crab infected with the RLB agent of MHS. 


\section{LITERATURE CITED}

Anderson IG, Shariff M, Nash G, Nash M (1987) Mortalities of juvenile shrimp Penaeus monodon, associated with Penaeus monodon baculovirus, cytoplasmic reo-like virus and rickettsial and bacterial infection, from Malaysian brackish water ponds. Asian Fish Sci 1:47-64

Bell TA, Lightner DV (1988) A handbook of normal penaeid shrimp histology. World Aquaculture Society, Baton Rouge, LA

Bonami JR, Pappalardo R (1980) Rickettsial infection in marine crustacea. Experientia 36:180-181

Brock JA (1988) Rickettsial infection in penaeid shrimp. In: Sindermann CJ, Lightner DV (eds) Disease diagnosis and control in North American marine aquaculture. Elsevier, Amsterdam, p 38-41

Drury RAB, Wallington EA (1967) Carleton's histological technique, 4th edn. Oxford Medical Publications, Oxford

Eddy F, Powell A, Gregorey S, Nunan LM and others (2007) A novel bacterial disease of the European shore crab, Carcinus maenas-molecular pathology and epidemiology. Microbiology 153:2839-2849

Field RH, Chapman CJ, Taylor AC, Neil DM, Vickerman K (1992) Infection of the Norway lobster Nephrops norvegicus by a Hematodinium-like species of dinoflagellate on the west coast of Scotland. Dis Aquat Org 13:1-15

Gonzalez-Escalona N, Romero J, Guzman CA, Espejo RT (2006) Variation in the 16S-23S rRNA intergenic spacer regions in Vibrio parahaemolyticus strains are due to indels nearby their tRNA ${ }^{\text {Glu }}$. FEMS Microbiol Lett 256: 38-43

Hasson KW, Wyld EM, Fan Y, Lingsweiller SW, Weaver SJ, Cheng J, Varner PW (2009) Streptococcosis in farmed Litopenaeus vannamei: a new emerging bacterial disease of penaeid shrimp. Dis Aquat Org 86:93-106

Li YY, Xia XA, Wu QY, Liu WH, Lin YS (2008) Infection with Hematodinium sp. in mud crabs Scylla serrata cultured in low salinity water in southern China. Dis Aquat Org 82:145-150

Editorial responsibility: Grant Stentiford, Weymouth, UK
Lightner DV (1996) A handbook of shrimp pathology and diagnostic procedures for diseases for cultured penaeid shrimp. World Aquaculture Society, Baton Rouge, LA

Lightner DV, Pantoja CR, Redman RM, Polous BT, Nguyen HD, Do TH, Nguyen TC (2008) Collaboration on milky disease of net-pen reared spiny lobsters in Vietnam. OIE Bull Anim Welf 2008-2:46-47

Lu YL, Chen WF, Wang ET, Guan SH, Yan XR, Chen WX (2009) Genetic diversity and biogeography of rhizobia associated with Caragana species in three ecological regions of China. Syst Appl Microbiol 32:351-361

Nunan LM, Poulos BT, Redman RM, le Groumellec M, Lightner DV (2003) Molecular detection methods developed for a systemic rickettsia-like bacterium (RLB) in Penaeus monodon (Decapoda: Crustacea). Dis Aquat Org 53:15-23

Nunan LM, Pantoja CR, Salazar M, Aranguren F, Lighter DV (2004) Characterization and molecular methods developed for detection of a novel spiroplasma pathogenic to Penaeus vannamei. Dis Aquat Org 62:255-264

OIE (Office international des épizooties) (2009) Aquatic animal health code, 12th edn. OIE-World Organization for Animal Health, Paris

Ramírez AS, Naylor CJ, Pitcher DG, Bradbury JM (2008) High inter-species and low intra-species variation in 16S-23S rDNA spacer sequences of pathogenic avian mycoplasmas offers potential use as a diagnostic tool. Vet Microbiol 128: 279-287

Shields JD, Behringer DC Jr (2004) A new pathogenic virus in the Caribbean spiny lobster Panulirus argus from the Florida Keys. Dis Aquat Org 59:109-118

Tamura K, Dudley J, Nei M, Kumar S (2007) MEGA4: molecular evolutionary genetics analysis (MEGA) software version 4.0. Mol Biol Evol 24:1596-1599. Available at www.kumarlab.net/publications

> Xu W, Xie J, Shi H, Li C (2010) Hematodinium infections in cultured ridgetail white prawns, Exopalaemon carinicauda, in eastern China. Aquaculture 300:25-31

Submitted: April 21, 2010; Accepted: July 19, 2010

Proofs received from author(s): August 25, 2010 